\title{
FCAW vertical welding of "V" butt plate in AC UHV transmission line construction
}

\author{
HanYang, ChenKerui, LiYang, QuBao \\ State Grid of China Technology, Ji'nan, Shandong 250000, China
}

\begin{abstract}
In twenty-first Century, China vigorously promoted the research and construction of AC and DC transmission technology in order to ensure the optimal allocation of energy resources in a large scale[1]. In the construction of AC UHV transmission line, the welding quality of tower and stiffening plate as the load bearing tower and the tension of the welded structure plays an important role in the overall quality of the steel structure. In the past, the welding process of semi automatic carbon dioxide solid core welding wire often has the characteristics of weld spatter not easy to clean up and low efficiency of welding. The semi-automatic $\mathrm{CO} 2$ flux cored arc welding, has the characteristics of current and voltage to adapt to a wide range, melting speed, has important significance for improving the process, this paper describes the technology in practical engineering applications, and developed the basic strategy of training for grid steel structure welding technicians. This paper also lists both V groove plate butt FCAW welding typical welding project, hope this welding process will continue to spread.
\end{abstract}

\section{Introduction}

The situation of the reverse distribution of energy resources and load center in China determines that UHV transmission technology has a wide application space in China. ${ }^{[2 .]}$ As the basic equipment of transmission line, the manufacturing process and welding quality of transmission line iron tower will have a root influence on the power construction project. The tower foot and stiffening plate of the transmission line tower are the components of the whole load of the transmission line, so the performance and quality of the structure will directly affect the line life. Transmission line tower tower foot and stiffened plate for welding, weld for " $\mathrm{T}$ " type joint production enterprises by manual semi-automatic carbon dioxide solid wire welding process, the welding foot size tower feet and stiffened plate, welding personnel in order to achieve the welding foot height higher, will regulate the corresponding welding to improve, which makes the weld spatter and heat output more, thus causing the weld spatter is difficult to clean up, difficult to ensure weld quality consequences. Therefore, semi-automatic flux cored wire carbon dioxide gas shielded arc welding, targeted training projects and appropriate welding specifications can effectively improve the welding quality of the tower and improve the production efficiency of transmission line towers.

\section{Specific process}

*Corresponding author: Email:hy19870604@163.com

\subsection{Pre welding preparation}

Parent material selection: The specimen should use the same selection and the actual production of material, now tower material for Q345, Q420, Q460 and other common low alloy high strength steel, in order to ensure the training of welding test pieces, we chose Q345 $\delta=12$ as a typical delta plate training project test piece for the parent material, see specimen size sketch figure.

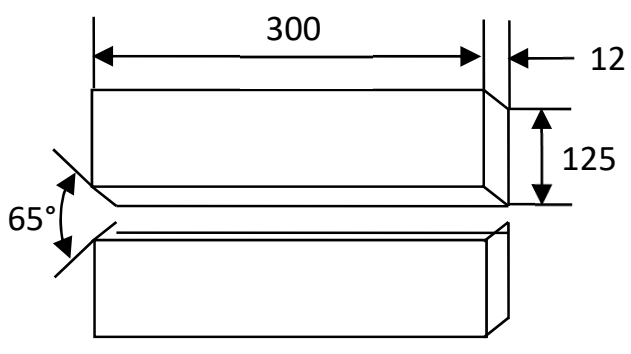

Figure 1 Schematic diagram of specimen specifications

Welding material selection: Since the tower foot and stiffened plate for thickness of welded components is large, so the selection of welding material is easy to use and adapt to a wide range of the voltage and current, welding speed, especially in all position welding, welding arc stable, solid wire flux cored wire is based on these requirements more obvious advantages. Because of the common low alloy steel with Q345 as the parent material, the type of E501T-1 $\Phi 1.2$ flux cored wire is used as the welding material. ${ }^{[3]}$

Protective gas: The protection gas used for welding Q345 ordinary low alloy steel can be protected by $\mathrm{CO}_{2}$ or 
$\mathrm{CO}_{2}+$ Ar mixed gas. However, considering the cost control and other factors, pure $\mathrm{CO}_{2}$ gas with purity of more than $99.5 \%$ is chosen as the protection gas. ${ }^{[4]}$

Welding equipment: Manual flux cored wire welding for gas shielded arc welding (FCAW) requires welding equipment to have good arc control ability for all position welding, especially in short circuit transition. Therefore, the fully digital controlled IGBT inverter welder is selected for welding power source. Through the full digital control, the welding parameters can be obtained from the small to the most stable droplet transfer, which is conducive to the control of molten pool forming in all position welding.

Slope clearance of test parts: Before the test pieces are cleaned, the slope of the specimen should be corrected first in order to ensure the straight slope. After the correction, the available angle grinder will test oil, a groove on both sides of the range of $20 \mathrm{~mm}$ corrosion to clean up, until the polished metallic luster.

\subsection{Assembly and positioning welding of the specimen}

Assembly gap: $2 \mathrm{~mm}$ at the beginning of the welding end and $3 \mathrm{~mm}$ at the end welding end.

The positioning welding: solder joint specimen groove located at both ends, the length is less than or equal to $20 \mathrm{~mm}$, and it is the same welding welding material for welding, welding must be solid and reliable, produced large deformation to prevent cracking or welding, solid solder joint after positioning to its side weld bead grinding and repair weld end after grinding should be sloped, so as to ensure the weld joint has good fusion, positioning welding position shown in Figure 2.

Specimen reverse deformation: in order to prevent larger deformation after welding, a certain angle of deformation can be reserved, the angle is 3 degrees, and 0.5 to $1 \mathrm{~mm}$ blunt edge can be reserved to prevent burn through. The size of the specimen assembly is shown in Figure 3.

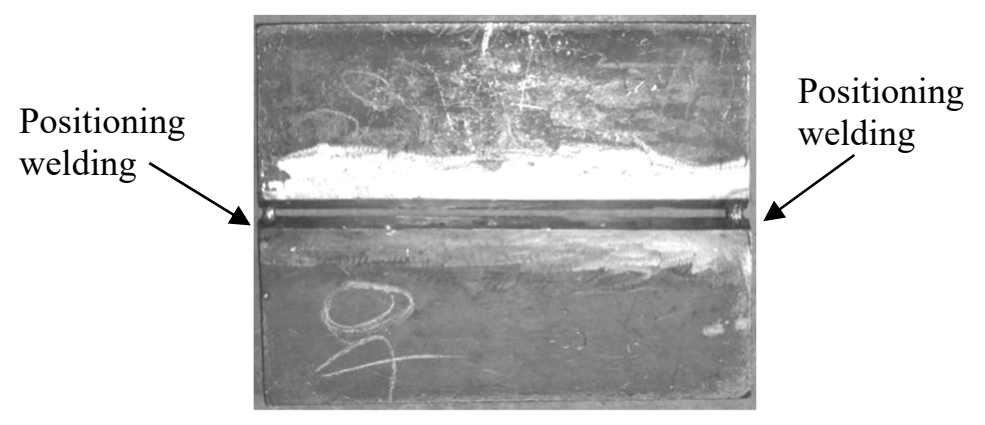

Figure 2 Positioning welding point diagram

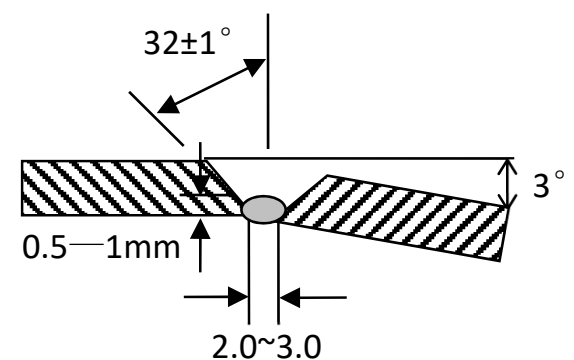

Figure 3 Sample assembly size diagram

\subsection{Welding specifications and parameters}

Number of welded pavement: four layers of four weld seam, as shown in Figure 4.

Welding parameters of each layer of weld seam: the welding parameters of each layer of weld seam are shown in Table 1.

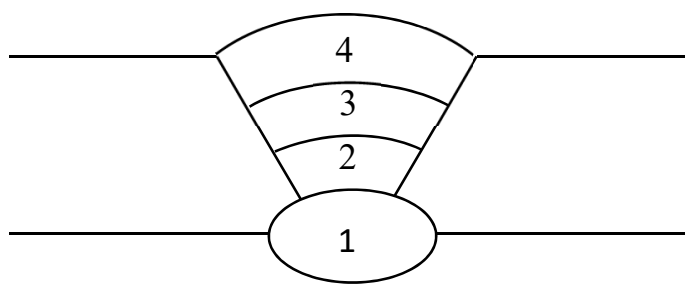

Figure 4 Track arrangement

\subsection{Key points of operation}

Backing welding: flux cored wire for welding in all positions, only the smaller the welding parameters can better control the shape of molten pool, but smaller welding parameters easily produce slag and incomplete fusion defects in the weld, in order to ensure the good weld quality and internal layer should be destroyed, seam welding the larger the operating parameters. 
Table 1 welding specification parameter list

\begin{tabular}{|c|c|c|c|c|c|c|c|}
\hline $\begin{array}{l}\text { operation } \\
\text { project }\end{array}$ & $\begin{array}{c}\text { welding } \\
\text { Method }\end{array}$ & $\begin{array}{c}\text { Power Supply } \\
\text { Polar }\end{array}$ & $\begin{array}{c}\text { Wire } \\
\text { diameter } \\
(\mathrm{mm})\end{array}$ & $\begin{array}{c}\text { welding } \\
\text { Electric } \\
\text { current (A) }\end{array}$ & $\begin{array}{c}\text { welding } \\
\text { Voltage } \\
\text { (V) }\end{array}$ & $\begin{array}{c}\text { Protective } \\
\text { gas } \\
\text { flow } \\
(\mathrm{L} / \mathrm{min})\end{array}$ & $\begin{array}{c}\text { Trunk } \\
\text { length (mm) }\end{array}$ \\
\hline Alignment welding & FACW & $\begin{array}{c}\text { DC back } \\
\text { connection }\end{array}$ & $\Phi 1.2$ & $160-160$ & $21-22$ & $12-15$ & $10-15$ \\
\hline Root layer soldering & FACW & $\begin{array}{c}\text { DC back } \\
\text { connection }\end{array}$ & $\Phi 1.2$ & $140-160$ & $20-21$ & $12-15$ & $10-15$ \\
\hline Filling layer welding & FACW & $\begin{array}{c}\text { DC back } \\
\text { connection }\end{array}$ & $\Phi 1.2$ & $140-160$ & $20-21$ & $12-15$ & $10-12$ \\
\hline Cover layer welding & FACW & $\begin{array}{c}\text { DC back } \\
\text { connection }\end{array}$ & $\Phi 1.2$ & $150-160$ & $20.5-21$ & $12-15$ & $10-12$ \\
\hline
\end{tabular}

Arc starting method: first, the welding torch is located at the lower part of the test part, and the switch ignites the ignition arc at the side slope of the track. The angle of welding torch should be kept right when starting arc, the dip angle of the welding gun and the test piece is 70 $80^{\circ}$ degrees, and the angle between the two sides of the slope is $90^{\circ}$ degrees, as shown in figure 5-a,b.
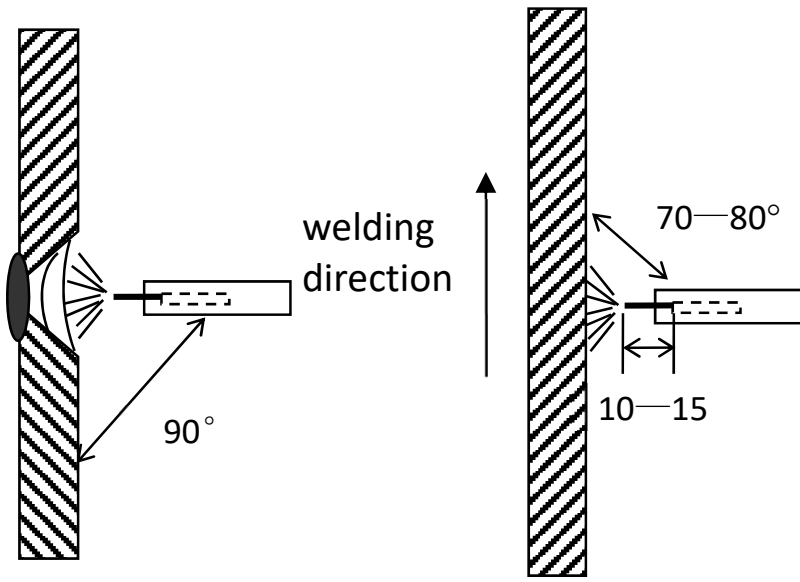

Figure5-a Circumferential angle of welding gun

Operation method: after the ignition of the arc, the left and right welding guns are welded to the end of the positioning welding, and the formal welding can be carried out behind the welding holes. When welding by arc welding method, welding torch from the left to the right side of the arc groove swing stop groove appeared the melt hole out, to the reciprocating action (always kept from left to right and then right to left from the swing arc), the operation should be just, and in an arc not completely cooled before the next arc ignition, the arc groove side to stay in time according to the flexible control of the size of the hole (molten melt hole when appropriate to shorten the residence time, melt hole hours to increase the residence time properly). Pay attention to the control of welding melt hole size, melt hole should not be too large, keep the bevel
Figure5-b Axial tilt angle of welding gun

edge of each side of melting $0.5-1 \mathrm{~mm}$ is appropriate, the arc swing process if the melt hole is not obvious should decrease the arc swing width, and a little pause in the root gap, melt hole is too large should increase swing width in order to avoid or reduce the frequency of arc breaking, back weld high or welding defects.

Methods: arc shrinkage defects or arc crater crack etc. in order to avoid, should the arc swing to one side and bottom bead, 1/3 - 1/2 $1-2$ times fast welding arc in molten pool.

The thickness of bottom welding layer is suitable for the $3 \mathrm{~mm}$ and back $1-1.5 \mathrm{~mm}$ of the front weld. After the welding, the slag and spatter should be cleaned up.

Filling welding: the filling seam is two layers and two channels, the arc is sawtooth and the arc is welded. The method of arc swing is shown in Figure 6. 


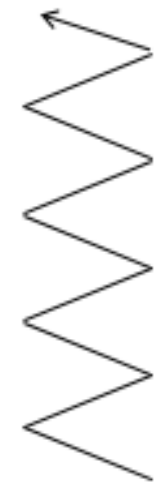

Figure6 Sawtooth arc oscillating diagram

Operation method: press the switch from the lower end of the weld arc welding torch, maintain appropriate welding torch inclination, as shown in Figure 5 - A, 5 - B; the stability of arc after the zigzag swing, swing during the stay in the arc groove on both sides of the time is slightly larger than the weld center, so as to fully guarantee the good fusion weld groove. When the second layer is filled and welded, when the arc swings to 1 to $1.5 \mathrm{~mm}$ from the edge of the groove, it should stay slightly and swing to the opposite side groove, so that there will be some allowance for the welding of the cover layer. The section of the second layer filler layer should be "U", as shown in Figure 7.

The end of the filling arc: the same operation method and layer arc method, the intermittent gun switch fill crater. After welding, the slag and spatter should be cleaned up.

Cover welding: the cover layer is one single single channel weld, and the sawtooth arc welding method is used. The seam forming of the cover layer should be straight, beautiful and without exceeding the standard.

Operation method: cover surface welding. Welding arc swaying to the edge of both sides should be slightly pause. Observe the weld pool and groove edge fusion about $1 \mathrm{~mm}$, then swing to the opposite side groove. At this time, the

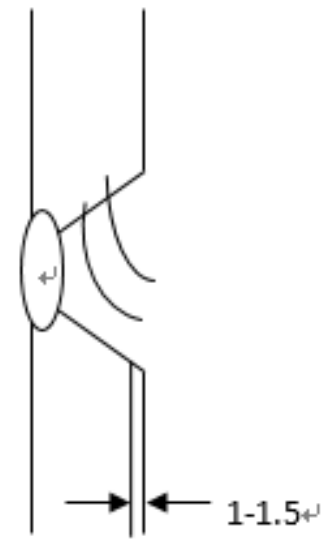

Figure6 Cross section diagram of filling layer

spans of the molten pool formed by two oscillating times are not easy to oversize, so as to avoid disjointing and unfusing. The pool should always be oval in shape, the size should be uniform, and the slag should be closely followed with the molten pool to keep the pool clear and bright.

The end of the filling arc: the method of arc arc covering layer with the same filling layer.

\subsection{Key points of operation}

The appearance and internal inspection of the specimen shall be in accordance with the relevant regulations of the DL/T 679-2012 welder technical examination regulations. ${ }^{[5]}$ The specific inspection contents are as follows:

The welds should be uniform and tidy, and the edges of the weld should be smooth and smooth to the base material; the shape size and the quality of the weld surface should be in accordance with the rules in table 2 , table 3 respectively.

Table 2 allowable size range of weld shape

\begin{tabular}{|c|c|c|c|c|c|c|}
\hline Weld form & \multicolumn{2}{|c|}{ Weld residual height } & \multicolumn{2}{|c|}{$\begin{array}{c}\text { Weld residual height } \\
\text { difference }\end{array}$} & \multicolumn{2}{|c|}{ Weld width } \\
\hline $\begin{array}{c}\text { Docking } \\
\text { Weld line }\end{array}$ & $\begin{array}{c}\text { Plane } \\
\text { position } \\
\text { welding }\end{array}$ & $\begin{array}{c}\text { Other } \\
\text { positions }\end{array}$ & $\begin{array}{c}\text { Plane } \\
\text { position } \\
\text { welding }\end{array}$ & $\begin{array}{c}\text { Other } \\
\text { positions }\end{array}$ & $\begin{array}{c}\text { Slope } \\
\text { widening } \\
\text { ratio }\end{array}$ & $\begin{array}{c}\text { Widening of } \\
\text { each side }\end{array}$ \\
\cline { 2 - 7 } & $0-3$ & $0-4$ & $\leq 2$ & $\leq 3$ & $\leq 6$ & $\leq 3$ \\
\hline
\end{tabular}

Table 3 allowable size range of weld shape

\begin{tabular}{|c|l|}
\hline Defect name & \multicolumn{1}{|c|}{ Defect allowable range } \\
\hline $\begin{array}{c}\text { Cracks, non fusion, surface } \\
\text { blowholes and slag inclusion }\end{array}$ & Not allow \\
\hline Undercut & $\begin{array}{l}\text { The depth is not more than } 0.5 \mathrm{~mm} \text {, and the total length of edge bite on both } \\
\text { sides of the weld does not exceed } 10 \% \text { of the full length of the weld. }\end{array}$ \\
\hline Non weld penetration & $\begin{array}{l}\text { The depth is not more than } 15 \% \text { of the thickness of the specimen, and it is } \\
\text { not more than } 2 \mathrm{~mm} \text {. The total length is not more than } 15 \% \text { of the full length } \\
\text { of the weld. }\end{array}$ \\
\hline Heel protruding & $\begin{array}{l}\text { A pipe piece or a pipe with a diameter greater than or equal to } 108 \mathrm{~mm} . \text { The } \\
\text { height is not more than } 3 \mathrm{~mm} \text {. The pipe diameter is less than } 108 \mathrm{~mm} \text { in }\end{array}$ \\
\hline
\end{tabular}




\begin{tabular}{|c|c|}
\hline & diameter $85 \%$ ball shall prevail. \\
\hline Sunken & $\begin{array}{l}\text { 1. When T } \leq 6 \mathrm{~mm} \text {, depth of not more than } 10 \% \text { of the thickness; when } \\
\mathrm{T}>6 \mathrm{~mm} \text {, depth of not more than } 15 \% \text { of the thickness, and not more than } \\
2 \mathrm{~mm} \text {. The total length is not more than } 10 \% \text { of the full length of the weld. } \\
2 . \text { The depth is not more than } 15 \% \text { of the thickness, and it is not more than } \\
2.5 \mathrm{~mm} \text {. The total length of the weld is not more than } 10 \% \text { of the full } \\
\text { length of the weld, and the position of the weld is not specified. }\end{array}$ \\
\hline
\end{tabular}

The specimen wrong export value should not exceed $1.2 \mathrm{~mm}$ (less than $0.10 \mathrm{~T}$ and not more than $2.0 \mathrm{~mm}$ ); bending deformation should be less than or equal to 3 degrees.

Ray inspection is adopted for non-destructive testing of weld, and the quality grade of ray inspection is not less than the class II requirement stipulated in NB/T 470132015.

The specimen after the inspection of the radiographic test should also be subjected to the cold bending test. One of the specimens of the bending and back bending should be taken each. The test method should be in accordance with the provisions of GB/T 2653.

\section{Conclusion}

In order to improve the production efficiency of the steel structure, we must scientifically formulate the welding process and define the processing method according to the structural characteristics of the products and the actual situation of the enterprises. For the welding of tower and stiffening plate of transmission line tower, the flux cored wire gas shielded arc welding is selected as the welding method. It can effectively control the heat output and reduce the welding deformation and spatter. And through the typical welding process characteristics of products, targeted training programs are set up to train welding personnel, which can minimize costs and improve efficiency.

\section{References}

1. Liu Zhenya. Global energy Internet $[\mathrm{M}]$. Beijing: China Electric Power Press, 2015. 48-48.

2. Liu Zhenya. China electric power and energy $[\mathrm{M}]$. Beijing: China Electric Power Press, 2012. 161-161

3. Zou Cheng. Welding manual (welding of materials) [M]. Beijing: Machinery Industry Press, 2008.247252.

4. Zhang Yanmin. International welder training [M]. Harbin: Heilongjiang people's press, 2002. 53-53

5. ]DLT 679-2012, specification for welder technology assessment [S]. 